\title{
Radially Anisotropic Ring/Arc-Shaped Rare-Earth Bonded Magnets Using a Self-Organization Technique
}

\author{
Fumitoshi Yamashita, Shinichi Tsutsumi, and Hirotoshi Fukunaga, Member, IEEE
}

\begin{abstract}
We developed a new technique using self-organization of binder that enabled the alignment of a molecular chain. By using this technique, we controlled the flexibility of $\mathrm{Nd}-\mathrm{Fe}-\mathrm{B}$-based rigid sheet magnets, transformed them into various shapes, and succeeded in preparing radially anisotropic ringor arc-shaped magnets. Optimizations of the consolidation process of the self-organization binder under a transverse alignment field and the transformation process into various specific shapes realized radially anisotropic magnets with $160 \mathrm{~kJ} / \mathrm{m}^{3}$ in $(\mathrm{BH})_{\max }$.

Index Terms-Flexible bonded magnet, hydrogenation, disproportionation, desorption, and recombination (HDDR)-Nd-Fe-B powder, radially anisotropic magnet.
\end{abstract}

\section{INTRODUCTION}

I SOTROPIC ring-shaped $\mathrm{Nd}-\mathrm{Fe}-\mathrm{B}$ bonded magnets made by the melt-spinning method, typically $25 \mathrm{~mm}$ or less in outer diameter, have been generally applied to small motors for office automation, audio-visual equipment, personal computers, and their peripheral equipment. They are prepared by the compacting technique, and have a typical $(\mathrm{BH})_{\max }$ value of $80 \mathrm{~kJ} / \mathrm{m}^{3}$. From the viewpoint of reduction in current consumption and further miniaturization of such motors, however, developments of new types of rare-earth bonded magnets with superior magnetic properties such as $160 \mathrm{~kJ} / \mathrm{m}^{3}$ in $(\mathrm{BH})_{\max }$ are strongly requested. Although usage of anisotropic $\mathrm{Nd}-\mathrm{Fe}-\mathrm{B}$ powder made by the hydrogenation, disproportionation, desorption, and recombination (HDDR) process is one of promising methods of preparing magnets for small motors beyond conventional isotropic $\mathrm{Nd}-\mathrm{Fe}-\mathrm{B}$ bonded magnets, the magnetic properties of radially anisotropic ring-shaped magnets deteriorated when their outer diameter is decreased down to approximately $25 \mathrm{~mm}$. Therefore, anisotropic $\mathrm{Nd}-\mathrm{Fe}-\mathrm{B}$ bonded magnets have not been mainly applied to small motors up to now.

In order to overcome the above difficulty, we developed a new technique using self-organization of a binder, which enabled the alignment of a molecular chain. By using this technique, we controlled the flexibility of $\mathrm{Nd}-\mathrm{Fe}-\mathrm{B}-$ based rigid sheet magnets (approximately $1 \mathrm{~mm}$ in thickness), transformed them into various shapes, and succeeded in preparing radially anisotropic ring- or arc-shaped bonded magnets previously [1]-[3]. As a re-

Manuscript received October 16, 2003.

F. Yamashita and S. Tsutsumi are with Motor Technology Center, Matushita Electric Industrial Co., Ltd., Osaka 574-0044, Japan (e-mail: yamashita.fumitoshi@jp.panasonic.com).

H. Fukunaga is with the Faculty of Engineering, Nagasaki University, Nagasaki 852-8521, Japan (e-mail: fukunaga@ net.nagasaki-u.ac.jp).

Digital Object Identifier 10.1109/TMAG.2004.830185

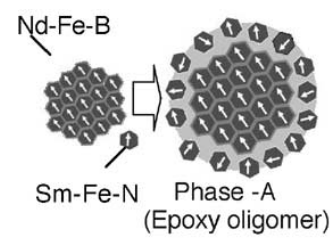

(a)

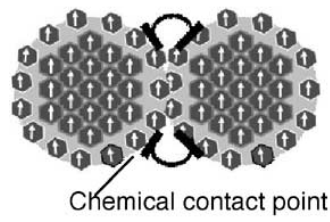

(c)



(b)

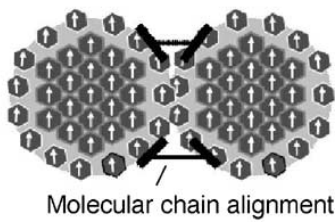

(d)
Fig. 1. Schematic representation of self-organization phenomenon of binder, together with two kinds of anisotropic magnetic powder. (a) Encapsulation. (b) Solidification. (c) Self-organization. (d) Transformation.

cent achievement, optimizations of the consolidation process of the self-organization binder under a transverse alignment field and the transformation process into various specific shapes realized radially anisotropic magnets with superior magnetic stabilities. Their $(\mathrm{BH})_{\max }$ value exceeded $160 \mathrm{~kJ} / \mathrm{m}^{3}$, even if their outer diameter is less than $25 \mathrm{~mm}$.

\section{EXPERIMENT}

\section{A. Materials}

HDDR Nd-Fe-B (53-150 $\mu \mathrm{m}$ in particle size, $292 \mathrm{~kJ} / \mathrm{m}^{3}$ in $\left.(\mathrm{BH})_{\max }\right), \mathrm{RD}$ (reduction and diffusion) $\mathrm{Sm}-\mathrm{Fe}-\mathrm{N}(2-3 \mu \mathrm{m}$ in particle size, $310 \mathrm{~kJ} / \mathrm{m}^{3}$ in $(\mathrm{BH})_{\max }$ ) were used as starting materials. Solid epoxy-oligomer, blocked-isocyanate, and polyamide-12 including an adhesive agent were also used for the self-organization system for preparing radially anisotropic ring- or arc-shaped rare-earth bonded magnets.

\section{B. Preparation Processes}

Fig. 1 shows the self-organization phenomenon of the binder schematically, together with the two kinds of anisotropic powder used for a magnet. In the encapsulation process, cores and cells, which is called "Phase-A," were prepared by mixing HDDR $\mathrm{Nd}-\mathrm{Fe}-\mathrm{B}$ powder, $\mathrm{RD} \mathrm{Sm}-\mathrm{Fe}-\mathrm{N}$ powder, and epoxy-oligomer including blocked-isocyanate as shown in Fig. 1(a). Subsequently, 2 wt.\% of polyamide fine particle with adhesive agent ("Phase-B") and lubricant were dry-blended with "Phase-A" and compounded. Next, the powdery compound was consolidated into a green compact under a pressure 


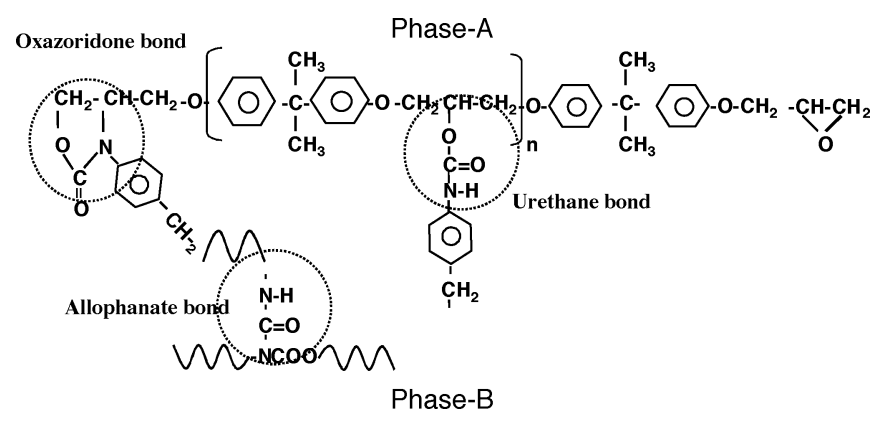

Fig. 2. Chemical structure of self-organized binder, which is prepared by reaction of "Phase-A," "Phase-B," and their chemical contact point. The chemical contact points are urethane, oxazoridone, and allophanate, respectively.

of $0.8 \mathrm{GPa}$, an elevated temperature of $50{ }^{\circ} \mathrm{C}$ to $160^{\circ} \mathrm{C}$, and a transverse field of $2 \mathrm{MA} / \mathrm{m}$ for alignment as shown in Fig. 1(b). Then, the prepared green compact was cured at $140{ }^{\circ} \mathrm{C}$ for $20 \mathrm{~min}$, and a sheet-shaped rigid bonded magnet (cured green compact) was obtained. As a result, the blocked-isocyanate forms the chemical contact point between "Phase-A" and "Phase- $B$ " as shown in Fig. 1(c). Consequently, the chemical structure of the self-organized binder is presumed as shown in Fig. 2.

Finally, by using self-organization of binder, which enabled the alignment of molecular chain as shown in Fig. 1(d), we controled the flexibility of $\mathrm{Nd}-\mathrm{Fe}-\mathrm{B}-$ based rigid sheet magnets, transformed them into various shapes, and succeeded in preparing radially anisotropic ring- or arc-shaped magnets. One of the examples is a radially anisotropic ring-shaped bonded magnet, which is approximately $1 \mathrm{~mm}$ in thickness and less than $25 \mathrm{~mm}$ in outer diameter. It could be prepared by rolling a sheet-shaped rigid bonded magnet with the rolling rate of approximately $2 \%$ to $5 \%$ at $60^{\circ} \mathrm{C}$ to $80^{\circ} \mathrm{C}$ and curing it. A radially anisotropic arc-shaped rigid bonded magnet was also obtained by stamping a sheet-shaped rigid bonded magnet at $120{ }^{\circ} \mathrm{C}$ under the pressure of $0.3 \mathrm{GPa}$.

\section{RESUlTS AND DISCUSSION}

\section{A. Optimizations of the Solidification Process}

Figs. 3-5 show examples of the optimizations of the consolidation process of the green compact under a transverse alignment field for HDDR Nd-Fe-B and their hybrid bonded magnets. The density and $(\mathrm{BH})_{\max }$ were measured by the Archimedes method and with a vibrating sample magnetometry (VSM) after magnetization by a pulsed field of $4 \mathrm{MA} / \mathrm{m}$, respectively. As shown in Fig. 3, the density and $(\mathrm{BH})_{\max }$ of the bonded magnet increased with an increase in the compacting temperature and saturated at $120{ }^{\circ} \mathrm{C}$. The $(\mathrm{BH})_{\max }$ value exceeded $160 \mathrm{~kJ} / \mathrm{m}^{3}$ at $100{ }^{\circ} \mathrm{C}$, reached the peak at $145^{\circ} \mathrm{C}$, and then decreased at $160^{\circ} \mathrm{C}$. This decrease can be attributed to the polymerization reaction of the binder. In the hybrid bonded magnets including $\mathrm{RD} \mathrm{Sm}-\mathrm{Fe}-\mathrm{N}$ powder, the $(\mathrm{BH})_{\max }$ value exceeded $160 \mathrm{~kJ} / \mathrm{m}^{3}$ at $80^{\circ} \mathrm{C}$. This temperature is lower than that for HDDR Nd-Fe-B bonded magnet shown in Fig. 4. Furthermore, the decrease in $(\mathrm{BH})_{\max }$ value of the hybrid bonded magnets due to curing in air was smaller than that of HDDR Nd-Fe-B bonded magnet as shown in Fig. 5.

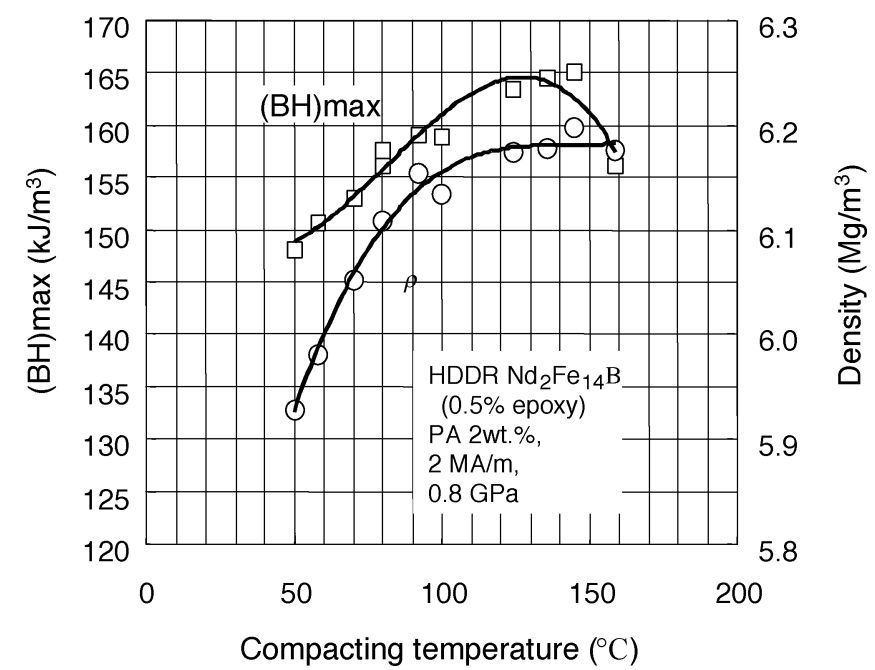

Fig. 3. Density and $(\mathrm{BH})_{\max }$ of the HDDR Nd-Fe-B bonded magnets as a function of compacting temperature. The $(\mathrm{BH})_{\max }$ and density were measured with a VSM after magnetization by a pulsed field of $4 \mathrm{MA} / \mathrm{m}$ and by the Archimedes method, respectively.

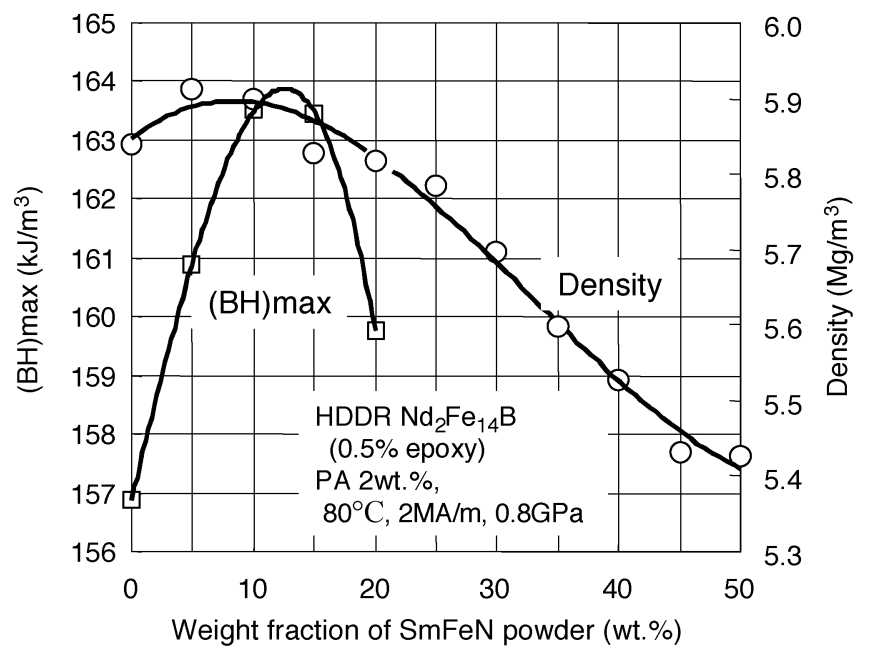

Fig. 4. Density and $(\mathrm{BH})_{\max }$ of the hybrid bonded magnets as a function of the fraction of RD Sm-Fe-N powder. The $(\mathrm{BH})_{\max }$ and density were measured with a VSM after magnetization by a pulsed field of $4 \mathrm{MA} / \mathrm{m}$ and by the Archimedes method, respectively.

\section{B. Magnetic Stabilities and Applications}

Generally, the effect of the initial flux loss, which is attributed to irreversible magnetization reversal at an elevated temperature, is more important than that of the long-term flux loss in applications to small electric motors. Thus, the initial flux loss at an elevated temperature was examined in air, and the results were shown in Fig. 6. As clearly seen in the figure, the initial flux loss of the hybrid bonded magnets was smaller than that of HDDR Nd-Fe-B bonded magnet despite their small coercivity $\mathrm{H}_{\mathrm{CJ}}$ values, and its value at $100^{\circ} \mathrm{C}$ is almost the same as that of the conventional isotropic $\mathrm{Nd}-\mathrm{Fe}-\mathrm{B}$ bonded magnet made from melt-spun powder.

Previously, we systematically evaluated the flux loss in bonded magnets with various values of $\mathrm{H}_{\mathrm{CJ}}$ and found that initial flux losses in some nanocomposite rare-earth bonded magnets were smaller than that of a conventional isotropic $\mathrm{Nd}-\mathrm{Fe}-\mathrm{B}$ bonded magnet, despite their small $\mathrm{H}_{\mathrm{CJ}}$ values [4], 


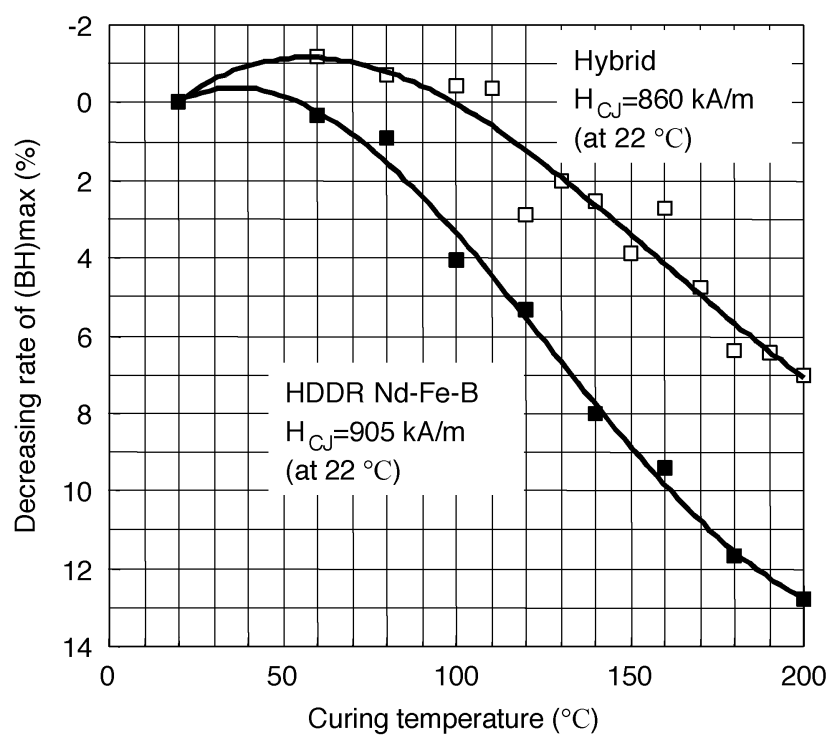

Fig. 5. Decrease in $(\mathrm{BH})_{\max }$ of hybrid bonded magnets due to curing, together with that of HDDR Nd-Fe-B bonded magnet. The curing was carried out for $20 \mathrm{~min}$ in air. The $(\mathrm{BH})_{\max }$ was measured with a VSM after magnetization by a pulsed field of $4 \mathrm{MA} / \mathrm{m}$.

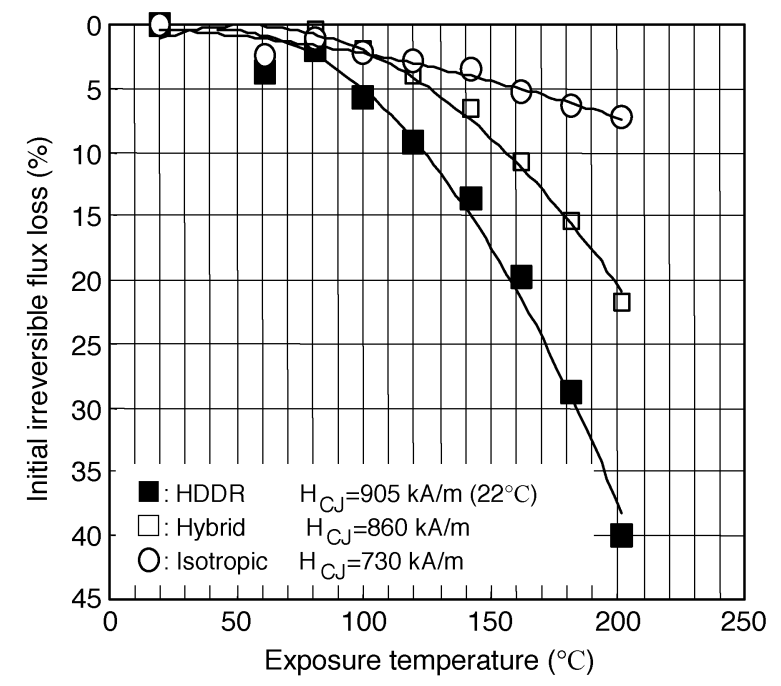

Fig. 6. Initial flux loss of a hybrid bonded magnet, together with flux losses of HDDR Nd-Fe-B and conventional isotropic Nd-Fe-B bonded magnet.

[5]. The above-mentioned improvement in the initial flux loss of a hybrid bonded magnets is possibly due to an improvement in the squareness $\left(\mathrm{Hk} / \mathrm{H}_{\mathrm{CJ}}\right)$ of the demagnetization curve at the exposed temperatures. The squareness of a demagnetization curve at $100{ }^{\circ} \mathrm{C}$ is shown in Fig. 7 .

Resultantly, the optimization of the solidification process of the self-organization binder under a transverse alignment field and the transformation process into various specific shapes realized radially anisotropic ring- or arc-shaped hybrid bonded magnets with superior magnetic stabilities as shown in Fig. 8. A transformation process into a specific shape reduced the flux value of the corresponding magnet, typically by $2.5 \%$ for a 1-mm-thick magnet. However, flux values of magnets obtained in this study were 1.3-1.6 times as large as those of conventional isotropic $\mathrm{Nd}-\mathrm{Fe}-\mathrm{B}$ bonded magnets with a $(\mathrm{BH})_{\max }$ values of approximately $80 \mathrm{~kJ} / \mathrm{m}^{3}$ made from

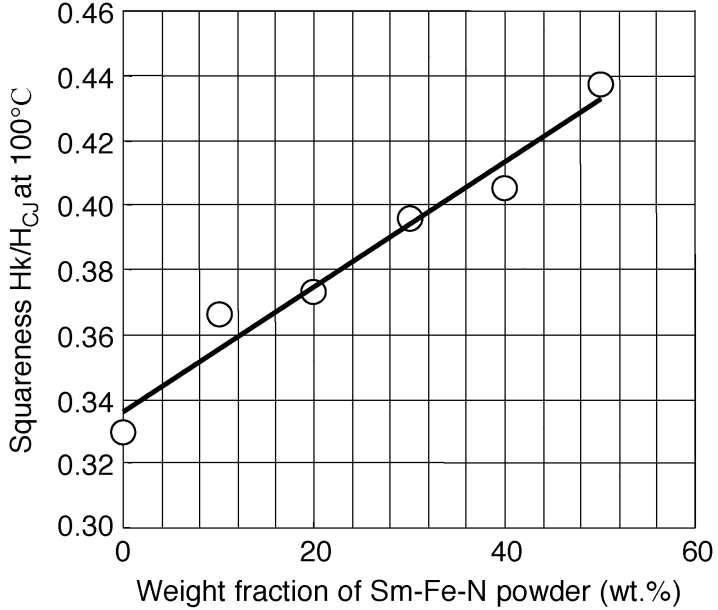

Fig. 7. Squareness $\left(\mathrm{Hk} / \mathrm{H}_{\mathrm{CJ}}\right)$ at $100{ }^{\circ} \mathrm{C}$ of the hybrid bonded magnets as a function of the fraction of RD Sm-Fe-N powder. The squareness was measured with a VSM after magnetization by a pulsed field of $4 \mathrm{MA} / \mathrm{m}$.

Ring shaped magnet after rolling out

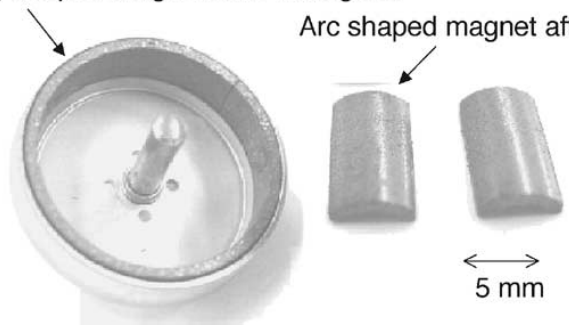

Fig. 8. External views of a radially anisotropic ring- and arc-shaped bonded magnets. The intended dimension of the ring shaped magnet are $23 \mathrm{~mm}$ in outer diameter and $1.05 \mathrm{~mm}$ in thickness. The intended dimensions of the arc-shaped magnet are $3.55,3.65,0.90$, and $5 \mathrm{~mm}$ in inside radius, outside radius, maximum thickness, and length, respectively.

melt-spun powder. Therefore, they can be applied to various small motors.

\section{CONCLUSION}

We developed a new technique, which utilizes the self-organization of binder, for the solidification process under a transverse alignment field and the transformation process into various specific shapes. This technique enabled to prepare radially anisotropic ring- or arc-shaped HDDR Nd-Fe-B/RD Sm-Fe-N hybrid bonded magnets with superior magnetic stabilities. Their $(\mathrm{BH})_{\max }$ value exceeded $160 \mathrm{~kJ} / \mathrm{m}^{3}$, even if their outer diameter is less than $25 \mathrm{~mm}$.

\section{REFERENCES}

[1] F. Yamashita, "Application of rare earth magnets in the small motor industry," in Proc. 17th Int. Workshop Rare-Earth Magnets Their Applications, Newark, DE, 2002, pp. 100-111.

[2] F. Yamashita, A. Watanabe, and H. Fukunaga, "Reduction in current consumption of small DC motor with rare-earth flexible bonded magnets prepared by powder compacting press and hot rolling," IEE Trans. FM, vol. 123, no. 2, pp. 146-152, 2003.

[3] _ - "New preparation method of anisotropic and isotropic Nd-Fe-B flexible bonded magnet for efficient small motors," IEEE Trans. Magn., vol. 39, pp. 2980-2982, July 2003.

[4] H. Fukunaga, S. Hayashida, Y. Kanai, and F. Yamashita, "Flux stability in nano-composite magnets," J. Magn. Magn. Mater., vol. 203, no. 1, pp. 304-306, 1999.

[5] Y. Kanai, S. Hayashida, H. Fukunaga, and F. Yamashita, "Flux loss in nano-composite magnets," IEEE Trans. Magn., vol. 35, pp. 3292-3294, Sept. 1999. 